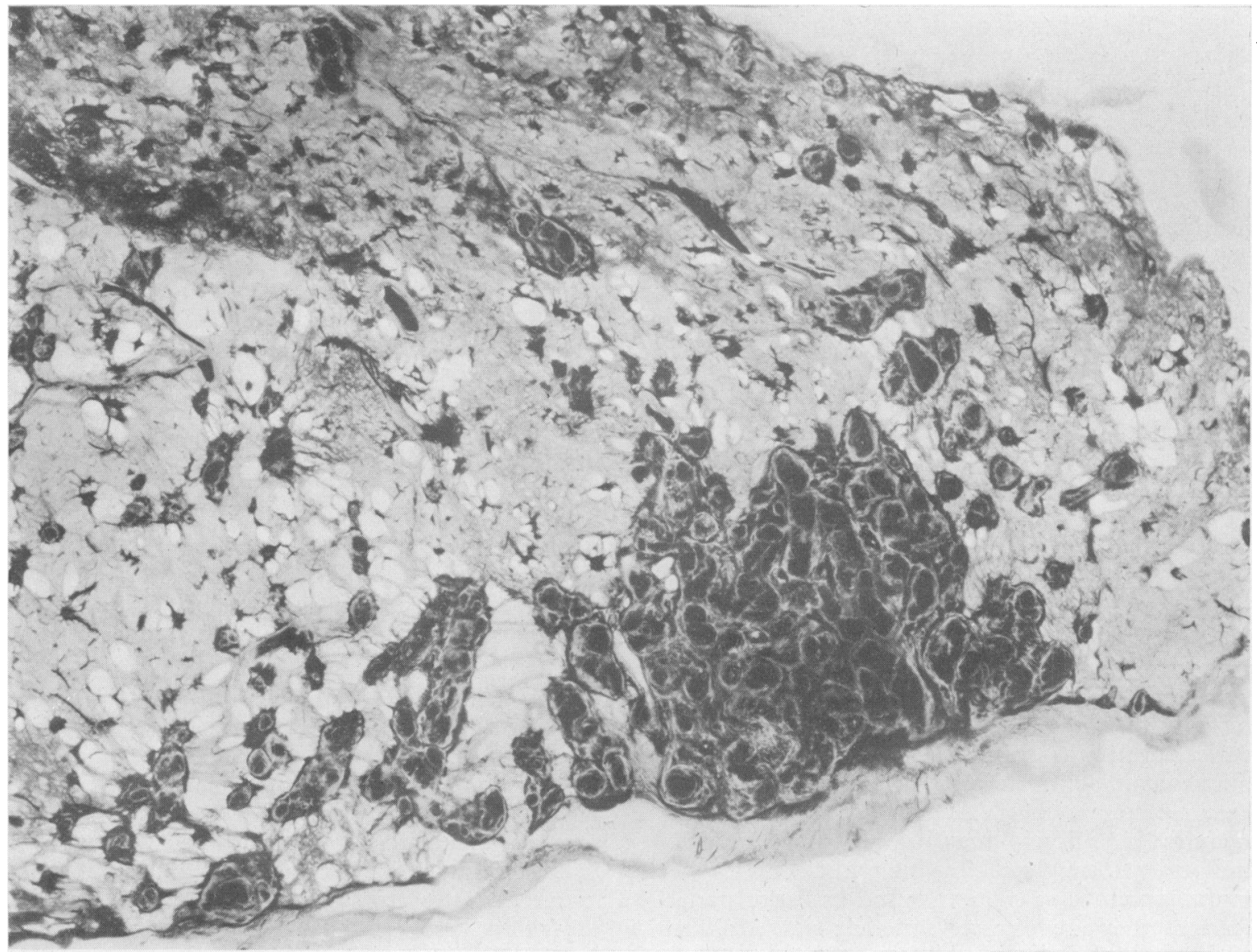

Fig. 1.-Silicosis. Upper part of the lung of a South African gold miner showing silicotic nodules.

\title{
THE PATHOLOGY OF PNEUMOCONIOSIS
}

\author{
By J. Gough, M.D.
}

Professor of Pathology and Bacteriology, Welsh National School of Medicine, Cardiff

\section{Introduction}

Ten years ago it appeared that pneumoconiosis in general could be explained by the presence of silicon dioxide (free silica) in a noxious dust and that the disease process was caused by this silica going into solution in the lung and in soluble form stimulating the formation of fibrous tissue. This interpretation seemed to explain most of the known facts and was supported by the experimental finding that silicon dioxide, capable of producing silicosis in animals, could be rendered inert by making the silica insoluble by coating it with iron (Kettle, 1932) or aluminium (Denny, Robson and
Irwin, 1939). The solubility theory of silicosis has been challenged however on the grounds that it does not give a straightforward explanation of all the known forms of pneumoconiosis and there is no simple correlation between the silicon dioxide content of a given dust and its pathogenicity. This problem will be discussed under the heading 'Experimental Silicosis.'

Another change in outlook has been the recognition that wide varieties of dust are capable of causing pneumoconiosis. Whereas in 1934, according to Kettle, the view was generally held that pneumoconiosis and silicosis were practically 
synonymous terms, there is now considerable evidence that other elements including aluminium and beryllium can produce pulmonary fibrosis.

With respect to the incidence of pneumoconiosis in Britain the most striking change in recent times has been the high certification rate of pneumoconiosis in the coal miners of South Wales, and the number of cases amongst them is numerically many times greater than that occurring in all other industries put together. Earlier this century coal mining was regarded as a healthy industry apart from accidents, but now, in one coal field at least, there is found a serious incidence of pneumoconiosis. This form of the disease will be considered in detail. Other varieties of pneumoconiosis will be dealt with more briefly, except that asbestosis and siderosis will not be included as they will be dealt with by other writers in this issue.

\section{Silicosis}

The basic lesion of classical silicosis is the silicotic nodule in which collagenous fibrous tissue is laid down, usually in a concentric arrangement, to form spherical nodules in which the dust particles can be identified. The anatomy and histology of these lesions is very similar in a wide variety of industries in which there is exposure to dust containing much free silica. Fig. I shows an example from a South African gold miner. The nodules in silicosis may be distributed fairly uniformly throughout the lung but tend to be more numerous in the upper and posterior parts. At first they are discrete but they may tend to coalesce. The disease is frequently associated with tuberculosis and it is often difficult to decide how much of the fibrotic process is due to the dust and how much to the associated infection. It has been suggested by Fallon (1937) that the similarity of tuberculous and silicotic nodules is due to the fact that both are caused by the action of lipoids from damaged endothelial cells. The tuberculosis associated with silicosis may be of the common caseating variety with extensive cavitation (Fig. 2), but often leads to the formation of large masses of fibrosis several inches in diameter. In the silicosis of gold miners Irvine (1938) found that the conjunction of a tuberculous infection with a silicotic lesion does not in general lead to the formation of an active spreading tuberculosis, but to a modification of the silicotic process resulting in the production of large masses of fibrous tissue of mixed silicotic and tuberculous origin. $\mathrm{He}$ points out that these mixed lesions are slowly progressive but tend ultimately to break down and initiate terminal active tuberculosis. The same author, together with Simson and Strachan (1930), found that even where the lesions do not show obvious evidence of tuberculous infection the latter can be demonstrated in a considerable $e_{0}^{\circ}$ number of instances by animal inoculation.

In man simple silicosis of the classical type may气 produce ill effects by the development of associated

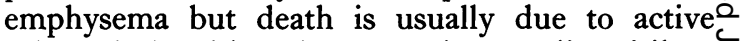
tuberculosis although congestive cardiac failure may also be the terminal event, consequent upon fibrosis of the massive type and emphysema. Theo mortality figures for South Africa show plainly,듬 however, that the liability to death bears a directo relation to the relative prominence of the ${ }_{\alpha}^{\Phi}$ tuberculous factor.

Silicosis, in contradistinction to asbestosis, does not predispose to carcinoma of the lung. The. Miners' Phthisis Medical Bureau of South Africa $\overrightarrow{\vec{H}}$ (1944) showed from post mortem studies that primary cancer of the lung is not more common in silicotic miners than in either non-silicotic miners 3 . or in a similar body of males in the generalif population. Vorwald and Carr (1938) andi Gardner (1940) on the basis of radiological\& examinations also found no evidence that silicosis 9 predisposes to carcinoma of the lung.

\section{Experimental Silicosis}

Nodular silicosis of the classical type has beẹp produced in experimental animals both by t exposure to dust in the atmosphere and also ty injection of suspensions of dust into the air passages of animals. There can be little doubt $\overrightarrow{0}$ that silica alone can produce a nodular fibrotic lesion and this may occur with silicon dioxide dusts of a high degree of purity.

According to the classical work of Gye and Purdy (1922, 1924) and Gye and Kettle (1922) the toxic action is to be explained by the silica $\frac{2}{\square}$ going into solution and Kettle (1932) showed that by coating the silica with iron and rendering it $\overrightarrow{\overrightarrow{0}}$ insoluble the material can be made non-toxic. This view received strong confirmation from the findings of Denny, Robson and Irwin (1939) who showed that the poisonous effects of silica can be을 neutralized by powdered metallic aluminium. To produce the neutralizing effect the two substances 3 . must be brought into direct contact and this results in the formation of a layer of aluminium 3 hydroxide on the silica particles, rendering the latter insoluble. They compared the effects of the inhalation of silica dust with those of inhaling the same dust mixed with aluminium. The mixture did not produce silicosis when breathed in high N concentration several hours a day for many months, while the disease developed in animals $N$ receiving the silica dust alone. Similar protection ${ }_{\sigma}^{\omega}$ was obtained when silica and aluminium were given at separate times during the day, proving that aluminium when inhaled could neutralize silica already in the lungs. In recent work King, 


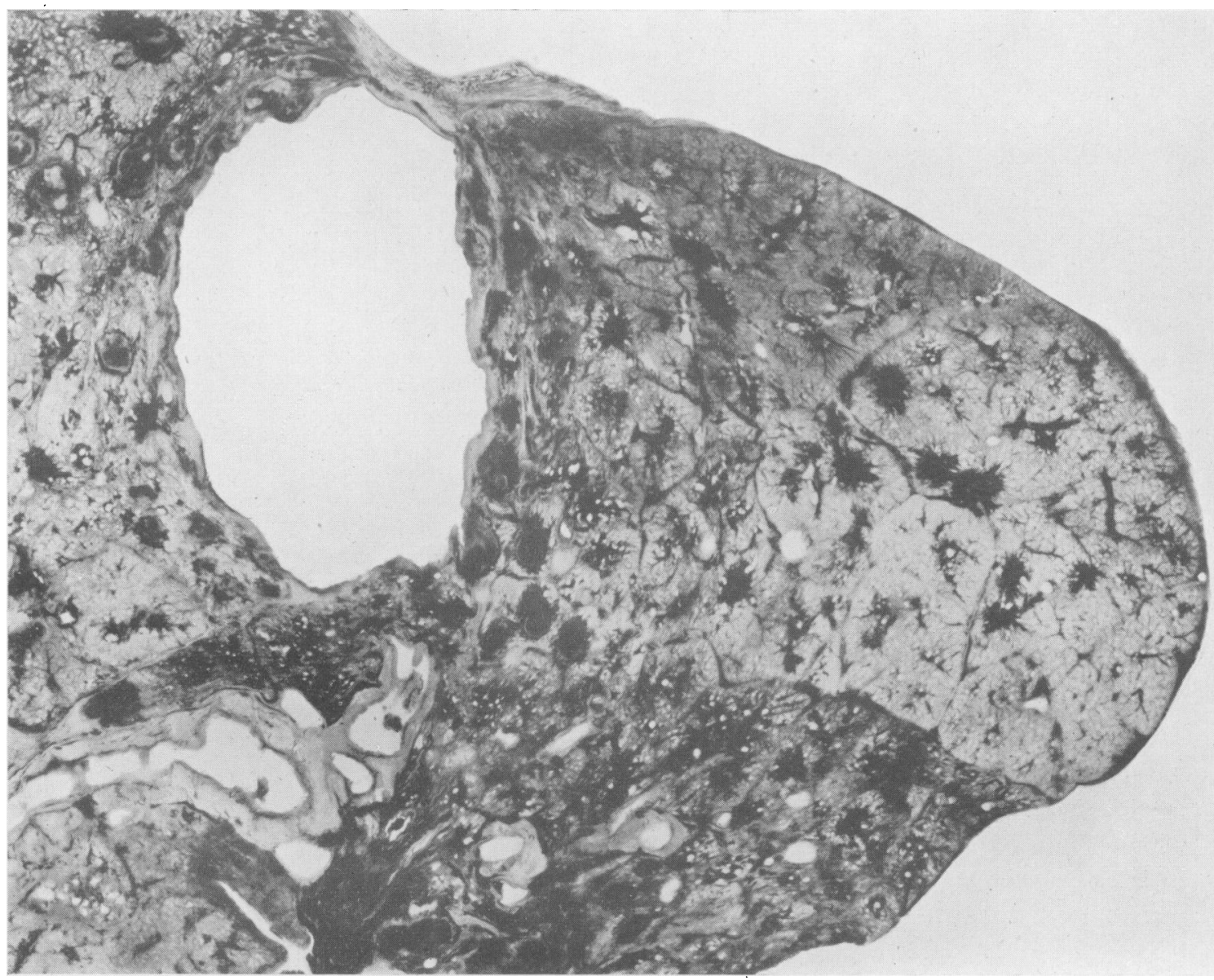

Fig. 2.-Silicosis with active tuberculosis. Lung of a Cornish tin miner. There is a tuberculous cavity in the middle zone with adjacent silicotic nodules.

Wright and Ray (1949) have also shown by inhalation experiments that the toxicity of silica can apparently be reduced by the action of aluminium.

In a critical study of the theories of silicosis King (1947) points out that according to the modern 'chemical' theory the toxic substance is thought to be silicic acid, and it might be supposed that the pathogenicity of any stone dust would bear a direct relation to the rate at which it will release silicic acid into solution. He points out that broadly speaking this is the case; quartz and flint which dissolve to the extent of $10 \mathrm{mg}$. of silica per roo cc. of blood and plasma are the most pathogenic, while shale and mica which are less soluble are also less pathogenic. There are, however, exceptions to this. Certain sandstones which have a low silica solubility have a high pathogenicity and olivine, a magnesium silicate of intermediate solubility, apparently causes no pulmonary disease in man and no fibrosis in the lungs of animals. King emphasizes that in mixed dusts some of the constituents may depress the solubility of the free silica component, thus shale dusts markedly depress the solubility of quartz dusts. This interaction of different components would appear to explain many of the apparent discrepancies in the toxic action of a dust expected from its total silica content. This, however, does not explain all the difficulties and King suggests that a possible explanation is that liberation of a toxic substance from silica in the body may be different from that which occurs in a test tube. He speculates on the possibility that within cells silicic acid may be released from quartz in a special toxic or ' nascent' form.

Some have attempted to interpret the pathological reactions to silica in terms of surface 


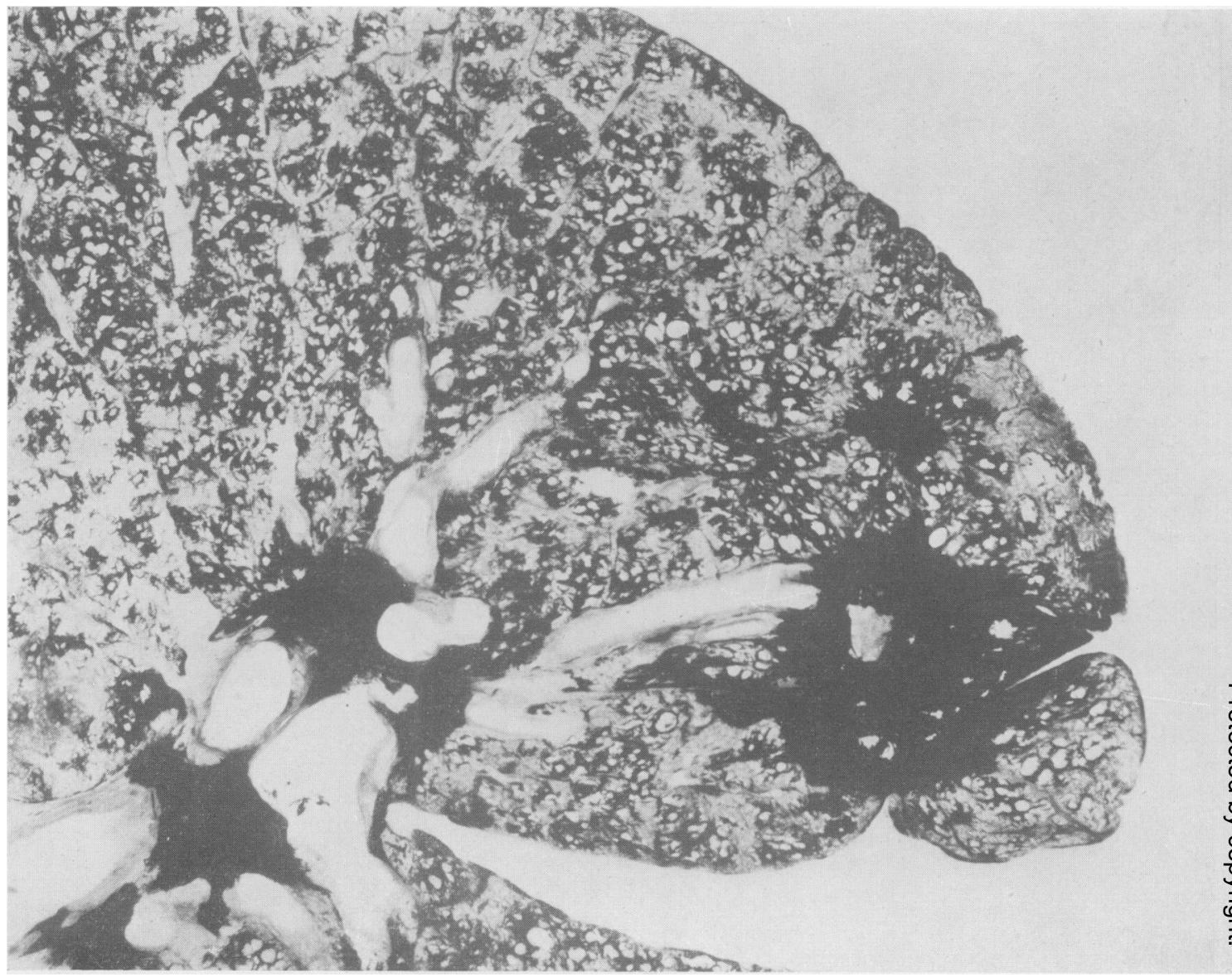

FIG. 3.-Coal zorker's pneumoconiosis. Most of the lung shows focal emphysema in relation to coal nodules. 'There is massive fibrosis at the apex of the lobe. Such fibrosis is considered to be due to superadded tuberculosis.

Photographs by Mr. F. E. Wentworth

activity of the particles and have inferred that recently formed particles are more active in respect of being able to produce disease than are older particles. Policard (1947) has stated that old dust such as sand in its natural state has become less pathogenic due to weathering. He considered this was due to the loss of bases and the intake of water by the mineral particles and that particles which had been thoroughly weathered have lost their effect on living tissues and are pathologically inert. King (1945) found that dust kept in a laboratory in a dry state for many years retains its pathogenicity. Nevertheless he has pointed out that particles repeatedly leached with water lose solubility and this phenomenon may be concerned in the weathering of dust. Gardner (1938) found that ' quartz stored in a reasonably dry building, but subject to marked variations in atmospheric humidity, did not lose its pathogenicity over a period of four years.' Likewise a sterile suspension of silica particles in physiological salt solution kept? in a refrigerator for many months neither in-응 creased nor decreased in capacity to excite re-3.

action in the tissues.
Although there are objections to the solubility hypothesis of silicosis it still seems to offer the most acceptable explanation. The problem is, however, by no means a simple one but apparent 을 discrepancies, in some cases at least, may be $>$ explained on the grounds that in mixed dusts some constituents may depress and others heighten the N solubility of silica.

The size of particles concerned in the production of silicosis is important. The ones which enterw the lung are mostly below $10 \mu$ and the majority are below $5 \mu$. King (1947) has shown that inco Ringer's solution there is increased solubility with reduction of particle size below 5 microns? 
and Gardner (1939) considers that the toxic action of quartz in chronic lesions is limited to particles of $3 \mu$ or less.

\section{Pneumoconiosis due to Silicates}

The question as to whether silicates are toxic when inhaled has been very much debated since Jones (1933) put forward the view that sericite, a potassium aluminium silicate, is the cause of much industrial silicosis, but of recent years this view has received very little support. Numerous instances of pneumoconiosis due to talc (hydrated magnesium silicate) have been described, however, in different parts of the world and the first case of this type in Britain proved by autopsy has been reported by McLaughlin, Rogers and Dunham (1949). 'These authors suggest that talc pneumoconiosis and asbestosis are similar diseases and that the former is caused only by the fibrous varieties of talc.

Numerous examples of granuloma have been described, caused by talc which has been deposited in the peritoneal cavity as a result of surgical operations.

Cases of pneumoconiosis have also been described in men exposed to a mica dust containing almost no free silica (Dreesen et al., 1940). The signs and symptoms were said to resemble those of silicosis.

King considers silicates less toxic than free silica because of their lower solubility and that silicates may reduce the toxicity of a mixed dust by depressing the solubility of quart\%.

\section{Coalworkers' Pneumoconiosis}

'I'his is described next because of its high numerical incidence and because it presents pathological features distinct from those found in silicosis.

Amongst coal miners there is a small percentage who develop classical silicosis. These are men engaged in drilling rock, cutting through strata which separate the coal seams. Some workers may engage entirely in this type of work and their lungs, as for instance those working in the sandstone strata in the east of South Wales, may show silicosis indistinguishable from that found in gold miners, tin miners and stone masons.

On the other hand the men who work on the coal seams, cutting the coal by hand picks or by machinery, and those engaged in loading coal, present a pneumoconiosis distinguishable from silicosis of the classical type. As with classical silicosis there appear to be two forms of the disease -one, simple pneumoconiosis, due to action of dust alone and the other, infected pneumoconiosis, due to the combined action of dust and infection.

In the simple form the dust is found in foci throughout the lungs in the form of black spots up to about $5 \mathrm{~mm}$. in diameter. The dust collects around the small bronchioles and their accompanying arteries, having been brought there from the alveoli by phagocytes. For the most part the dust remains within these cells, the general shape of which is preserved, although the nuclei are obscured. A delicate fibrosis consisting of reticulin fibres develops in the foci of dust. Fibrosis may not proceed beyond this stage or there may be the development of collagen. The latter does not develop to the same extent as in silicosis nor does it have the concentric disposition but runs irregularly or radially. The foci have a crenated edge with the processes extending into the unaffected tissues. In and around the coal foci the airspaces become dilated, giving a characteristic appearance described as focal emphysema (Fig. 3). This emphysema has also been described in classical silicosis, but it is very much more severe in the coal worker and the foci may enlarge and become confluent.

The focal emphysema appears to be due to some mechanical disturbance within the secondary lobules of the lung, as in these units it can beo seen that the emphysema starts around the bronchioles leaving a rim of unaffected lung along the interlobular septa, except in the most advanced stages. In focal emphysema there are no bullae projecting from the surface of the lung so that we have a condition unlike that of ordinary bullous emphysema.

Heppleston (I947) considered that the em-: physema is caused by a shrinkage of the fibrous tissue in the coal foci, while Rogers (1944) considered that there had been interference with the lumen of the terminal bronchioles leading to partial obstruction with trapping of air and consequent dilatation of the airspaces.

The noxious element in coal dust is not known with certainty. Coal always contains silica, including some quartz, so that although pneumoconiosis is in a different anatomical form from classical silicosis it may be a very modified form of the latter disease. 'The point to be emphasized, however, is that the dust formed from commercial coal is a noxious dust. Pneumoconiosis identical with that in coal miners is seen in coal trimmers, who are men who load coal into ships. In the past it has been argued that the respiratory disease in miners may be due to the fumes from the explosives used in getting the coal or to the rapid chilling due to travelling against the incoming air in those mines entered by slants. The occurrence of an identical form of the disease in men loading coal into ships shows that cold and fumes can be at most only contributory factors and that the essential cause is the inhalation of dust. 


\section{Infective Variety of Coalworkers' Pneumoconiosis}

The condition described above as simple pneumoconiosis seems to be due to the action of dust alone but superimposed upon it there is frequently a massive fibrosis which appears to me to be due to the combined action of infection and dust (Fig. 3). The masses tend to occur most frequently in the upper and posterior parts of the lungs, sometimes unilateral, sometimes bilateral. They may be several inches in diameter and are firm and rubbery in consistence. In the centres of the masses there are frequently spaces containing black inky fluid in which are crystals of cholesterol. In some cases the fluid is expectorated, leaving a ragged cavity. These cavities appear to be formed by necrosis of the tissue caused by obliterative endarteritis.

In about 40 per cent. of cases of massive fibrosis tubercle bacilli can be demonstrated in the lesions post mortem by culture or animal inoculation, and in those cases where no bacilli are found it is assumed that the infection has died out.

Cases are seen where there is superimposition of active tuberculosis on the simple pneumoconiosis foci and stages from the earliest infective change up to the formation of large fibrotic masses can be traced. In the past tuberculosis has been regarded as of low incidence in coal workers, but the form of tuberculous reaction which I have been describing does not usually give rise to caseation or to the usual symptoms of open tuberculosis. There is greater formation of fibrous tissue, the progress is very slow and the ill effects are principally on the pulmonary circulation, causing very marked right heart hypertrophy and frequently death is due to congestive cardiac failure. In a smaller percentage of cases the tuberculosis spreads more acutely and in these, in addition to the pneumoconiotic lesions, there is caseation and bronchopneumonic spread of the infection.

One other cause of death which occurs not infrequently is pulmonary arterial thrombosis. This commences in a branch of the artery in relation to an area of massive fibrosis and the thrombus is propagated towards the hilum of the lung.

The outstanding differences between coal workers' pneumoconiosis and classical silicosis are first, the former gives rise to more severe emphysema than the latter, and secondly the effects of tuberculosis are somewhat different in the two conditions; in classical silicosis the open type of tuberculosis is a common terminal event although heart failure from massive fibrosis also occurs; in coal workers, massive fibrosis leading to heart failure is the usual occurrence, whereas open tuberculosis is a less common complication.

\section{Graphite}

In the past graphite, like coal, has been re-⿳亠丷⿵冂丶 garded as innocuous but two recent papers (Harding and Oliver, I949), and Gloyne, Marshallo and Hoyle, I949) have described graphite pneumo- $\frac{\varrho}{c}$ coniosis in Britain. The disease is similar to that met with in coal workers and since naturalos graphite contains silica it may be that the diseaseo in graphite workers is also a modified silicosis.

\section{Aluminium}

It has been mentioned above that aluminium $\vec{D}$ has been found to reduce the toxic action of silica, but at the same time workers, particularly in $\vec{\omega}$ Germany (Goralewski, I943), have described as pneumoconiosis ascribed to dust of powderedo metallic aluminium. Among the clinical features 3 . was development of spontaneous pneumothoraxor in several cases. At post mortem, collagenousic fibrosis was found and dust particles were presento which could be distinguished from carbon by their? jagged outlines.

Hunter et al. (1944) found no pneumoconiogis in grinders of duralumin in Britain. It may ded in the case of the German workers that the sup $\frac{0}{0}$ stitution of other lubricants for stearin in the stamping process of making aluminium powder may have been responsible and also the amount $\& f_{-}^{\circ}$ dust in the atmosphere was increased in cos - $-\overrightarrow{0}$ sequence of unsatisfactory ventilation of wo -4 rooms resulting from the war-time blackot. Examination of material from the German casess shows that it is undoubtedly a pneumoconiosis so that aluminium dust must be regarded as a toxicon substance under certain conditions of exposure.

In connection with aluminium another newly- $\overrightarrow{\overrightarrow{0}}$ recognized form of pneumoconiosis may be con-3 sidered. This has been described in Canada by Shaver and Riddell (1947) and Shaver (1948) occurring in men exposed to the fumes arising ino the process of making the abrasive 'aloxite,' by heating bauxite (aluminium ore) with iron and coal. These men developed diffuse fibrosis an of emphysematous bullae, the latter tending to fuse together forming larger cavities. Rupture of these, giving rise to pneumothorax was a prominent? feature. The precise aetiology is uncertain as the exposure involves high concentrations of both aluminium and silica, both in a very fine state of division. Very finely divided silica such as the so-called ' 20 Angstrom silica' is known to have ${ }_{R}$ general toxic action but does not cause pneumo- $-\omega$ coniosis in experimental animals. Whatever be the noxious element in the fumes causing disease in aloxite workers the reaction in the lung is very. different anatomically from classical silicosis. 


\section{Beryllium}

Serious pulmonary disease has occurred in workers exposed to beryllium and its alloys and compounds (a summary has been given by the New York State Department of Labour, 1949). Cases have occurred principally in the U.S.A. in the electric light industry in the use of beryllium phosphors in making fluorescent lighting. There are two main varieties of the disease - an acute one which in severe form leads to massive pulmonary oedema and occurs principally in workers exposed to the soluble salts of beryllium in the refining industry, and usually within a few days of heavy exposure. The other is a chronic pulmonary granulomatosis developing several months to years after the commencement of exfosure, principally among workers handling beryllium phosphors but also in those exposed to the dust or fumes of the metal or oxide. The granuloma shows round cells and giant cells resembling sarcoidosis. No infection has been found to account for the condition and excess beryllium has been found in the lungs. In the more chronic form fibrosis is present. A case has been described by Agate (1949) in this country occurring in a laboratory worker exposed to beryllium.

\section{Cotton Dust}

Cotton dust is known to produce a variety of chest symptoms (byssinosis) but post mortem studies have not yet revealed any distinctive underlying lesions in the lung.

\section{Carborundum}

Perhaps the most surprising of all the recent findings is that of Bruusgaard (1948) who has found pneumoconiosis by radiographic examination of men exposed exclusively to carborundum dust (silicon carbide). Post mortem investigations will be awaited with interest. In his classical experiments Gardner (1923) showed that carborundum was not toxic to experimental animals. This was one of the most important facts in disposing of the theory that it was the hardness or sharpness of particles that caused damage in the lungs. It would be ironical if it were now found that carborundum produces pneumoconiosis. However, Gardner (1938) found in experimental animals that carborundum, together with tuberculous infection, produced a fibrotic reaction which may also explain the human cases.

\section{Bagasse}

One of the more recently recognized forms of pneumoconiosis is one ascribed to the dust of sugar canes. Hunter and Perry (1946) have described recent cases including one fatal one.
The men affected were engaged in breaking up bales of cane imported into this country.

Perry (1948) has described that " the bronchioles become filled with vegetable dust which swells under the influence of bronchial secretions, blocks the bronchioles and gives rise to small areas of collapse. When these areas become infected typical acute bronchiolitis and pneumonia result. In some cases the condition does not resolve and there develops a fibrosis of the lung with cough and sputum and much shortness of breath, together with radiographic changes showing thick bands of fibrous tissue traversing the lung field so as to simulate cavities. In one case necropsy revealed chronic bronchiolitis and bronchiectasis of similar distribution to that associated with dust diseases. No large cavities were found. Fungi may play an important role in breaking down the fibre into a-very fine vegetable dust and may possibly even render this toxic. Aspergillus is present in all specimens of bagasse dust, but probably takes no part in causing the disease. The appearances are certainly not those of silicosis. The disease resembles "Farmer's Lung," "Broken Wind " of horses, and in some ways byssinosis. These may all belong to a single group.'

\section{Summary}

The theories of the nature of silicosis are discussed.

The changes found in coal workers' pneumoconiosis are contrasted with those of classical silicosis.

Reference is made to pneumoconiosis due to graphite, talc, mica, aluminium, beryllium and bagasse.

I wish to thank Dr. L. W. Hale for the specimens from which the sections shown in Figs. I and 2 were made.

\section{BIBLIOGRAPHY}

AGATE, I N. (1948), Lancet, 2, 530.

BRUUSGAARD, A. (1948), Proc. Ninth Intern. Cong. of Ind. Med. London (in the press).

DENNY, J. J., ROBSON, W. D., and IRWIN, D. A. (1939), Canadian Med. Ass. $\mathcal{F}_{\text {., }} 40,213$.

DREESEN, W. C., et al.' (1940), U.S.A. Public Health Bulletin, No. 250. Washington Government Printing Office.

FALLON, J. T. (1937), Canadian Med. Ass. F., 36, 223.

GARDNER, L. U. (1923), Amer. Rev. Tuberc., 7, 344.

GARDNER, L. U. (1938), Silicosis and Asbestosis, edited by Lanza, A. J.

GARDNER, L. U. (1939), Report of the Director of the Saranac Laboratories.

GARDNER, L. U. (r940), 7. Amer. Med. Ass., II4. 535

GLOYNE, S. R., MARSHALL, G., and HOYLE, C. (1949), Thorax, $4,3 \mathrm{I}$.

GORALEWSKI, G. (1943), Dtsch. Tuber-bl., 17, 3.

GYE, W. E., and KETTLE, E. H. (1922), Brit. F. Exp. Path., GYE, W. W. E., and PURDY, W. J. (1922), Ibid., 3, 75.

GYE, W. E., and PURDY, W. J. (1924), Ibid., 5,238 .

HARDING, H. E., and OLIVER, G. B. (1949), Brit. F. Ind. Med. 6,9I.

HEPPLESTON, A. G. H. (1047), F. Path. and Bact., 59, 453.

HUNTER, D., et al. (1944), Brit. Y. Ind. Med., I, 150 .

HUNTER, D., and PERRY, K. M. A. (1946), Ibid., 3, 64.

IRVINE, L. G. (1938), Proc. Intern. Conf. on Silicosis in Genevo I.L.O. Studies and Reports, Series F. (Industrial Hygiene), No. 17, p. 151 . 
IRVINE, L. G., SIMSON, F. W., and STRACHAN, A. S. (1930), Proc. Intern. Conf. on Silicosis in Fohannesburg, I.L.O. Studies and Reports, Series F. (Industrial Hygiene), No. 13, p. 259.

JONES, W. R. (1933), $₹$. of Hyg., 33, 307.

KETTLE, E. H. (1932), F. Path. and Bact., 35, 395.

KETTLE, E. H. (1934), Ibid., 38, 201.

KING, E. J. (1945), M.R.C. Special Report Series, No. 250, p. 73. KING, E. J. (1947), Occ. Med., $4,26$.

KING, E. J., WRIGHT, B. M., and RAY, S. C. (1949), Paper read to the Path. Soc., Great Britain, January, 1949.

MCLAUGHLIN, A. I. G., ROGERS, E., and DUNHAM, K. C. (1949), Brit. $\mathcal{F}$. Ind. Med., 6, 184 .

MINERS' PHTHISIS MEDICAL BUREAU OF SOUTH AFRICA (1946), Report for the Three Years ending fuly $3 \mathrm{I}$, 1944 (South African Government Printer).
NEW YORK STATE DEPARTMENT OF LABOUR (1949) Monthly Review, 28, No. 4, April.

PERRY, K. M. A. (1948), Proc. Ninth Intern. Cong. of Ind. Med? London (in the press).

POLICARD, A. (1947), Proc. Conf. of the Institution of Minin? Engineers and Institution of Mining and Metallurgy, London p. 24 .

ROGERS, E. (1944), Paper read to the British Tuberculosis Associa tion.

SHAVER, C. G. (1948), Radiology, 50, 760.

SHAVER, C. G., and RIDDELL, A. R. (1947), f. Ind. Hyg. and Tox., 29, 145 .

VORWALD, A. J., and CARR, J. W. (1938), Amer. F. Path., 14, 49

\title{
PNEUMOCONIOSIS IN COAL MINERS
}

\author{
By J. C. McVittie, M.B., Сн.B., D.P.H. \\ Senior Medical Officer, Pneumoconiosis Medical Panel, Swansea
}

In his contribution Dr. Meiklejohn has traced historically the recognition of a relationship between disease and dusty occupation, and has shown that the ancients were aware of the industrial risk and that they, in fact, attributed the damage in some degree to the dust they inhaled. Until 1831 English medical literature had been destitute of a single treatise on diseases of trades and professions. In that year Gregory described the postmortem findings in a case of pneumoconiosis 'with black infiltration of the whole lungs' in a Scottish coal miner. Subsequently there appeared a number of references to pulmonary disease in coal miners, and valuable and critical surveys of the literature appear in an excellent paper on ' Coal Miner's Lung' by Lyle Cummins and Sladden, in the first report (medical studies) dealing with chronic pulmonary disease in South Wales coal miners published by the Medical Research Council in 1942, and in the scholarly and comprehensive study of the disease by Fletcher. Although the reference to coal miners' pneumoconiosis had priority in our literature, the later studies were concerned chiefly with miners' phthisis in metalliferous mines and with silicosis in other industries, and there was considerable delay in bringing workers in the industries within the scope of the Workmen's Compensation Act. In 1907 the Committee on Compensation for Industrial Diseases recommended that the question of scheduling silicosis (fibrosis due to the inhalation of free silica) should be kept in abeyance for the time being. Later, owing to successful measures adopted in the gold mining industry in South Africa under successive Miners' Phthisis Acts, pressure was brought to bear on the Home Office to deal with the subject. Pressure was brought not only by medical men but by workers and their representatives who werei concerned about the incidence of the disease, and who were alert to the fact that increasing sickness? and disability were associated with changing cono ditions underground. In 1925 Grenfell presentedP the evidence he had collected in South Wales. In one year 22 cases (including 12 deaths) in drillers and 'hardheaders' had been collected from fine collieries. It was emphasized that in one per ticular pit the disabled men, whose ages ranged from 22 to 45 years, worked in the same place 90 ro heading. Four of the group had died and pogtte mortem evidence was available. In the follo ing year Tattersall reported the tragic story of a group of rock drillers in another area. As a resulę of these and other representations a method wasi devised of dealing with the difficulties of theD situation in this country by a system of ' schemes $\stackrel{\Omega}{?}$ each applicable to a particular industry or group of industries. Thus the Various Industries, (Silicosis) Scheme, r928, applied to all workmen employed at any time on or after January I, 1929 in 'the drilling and blasting in silica rock in or incidental to the mining or quarrying of othe minerals,' and by it silica rock was defined as. containing not less than $5^{\circ}$ per cent. free silica This scheme identified the disease with particulare occupations and with particular working places, 0 and the drillers, brushers and hardheaders were required to prove the analysis of rock. Theres was, too, a strange inconsistency between the above scheme and the Refractories Industriess (Silicosis) Scheme which came into force in 1919N The latter embraced compensation for partian incapacity as well as death and total incapacity Certification under the 1928 scheme was by a certifying surgeon who was not required to makean X-ray examination. These anomalies wer@ 